\title{
A Novel Method for Electricity Generation from Footsteps Using Piezoelectric Transducers
}

\author{
D. Sathish ${ }^{a}$, C. Srisailam ${ }^{b}$, D. Harsha ${ }^{c}$ and K. MuralidharGoud ${ }^{d}$ \\ A Department of EEE, Chaitanya Bharathi Institute of Technology (A), Gandipet, Hyderabad, T.S, India-500075. \\ B Department of EEE, Chaitanya Bharathi Institute of Technology (A), Gandipet, Hyderabad, T.S, India-500075. \\ ${ }^{C}$ Department of EEE, Chaitanya Bharathi Institute of Technology (A), Gandipet, Hyderabad, T.S, India-500075. \\ D Department of EEE, Vardhaman College of Engineering, Shamshabad, Hyderabad, T.S, India-509218
}

Article History: Received: 11 January 2021; Accepted: 27 February 2021; Published online: 5 April 2021

\begin{abstract}
The process of generation of mechanical energy of human footsteps and converting into electrical energy using piezoelectric transducer is discussed in this paper. This method of generation comes under the Energy scavenging section of renewable resources where wasted energy during regular processes such as heat during exothermic reactions is captured and converted. With the increase in energy consumption from handy electronic devices, the concept of harvesting alternative nonconventional energy in highly density population regions is a new interest of late. The model is a focused spring action between two tiles on to the piezoelectric transducers. This model contracts during a footstep and therefore allowing the mechanical input onto the transducers and converting this input into electrical output. This process is focused on footsteps upon multiple units across a pathway to generate maximum output with minimal monitoring. This type of generator is simply a secondary backup to coal or hydro power generation. The main feature of such generator is that this requires no conscious thought on the user's part.
\end{abstract}

Keywords: Piezoelectric sensors, Generation, Energy harvesting, PZT, Footsteps.

\section{Introduction}

New research for alternative energy sources has been of interest for the past decade on the eve of heavy decline in the fossil fuels. This research paved a way to rise of energy scavenging techniques (Songsukthawan, 2017). These techniques help us to capture and convert the dissipated energy from various chemical reactions or machinery processes. There are many energy scavenging techniques like capturing the surrounding heat during exothermic chemical reactions, heat dissipated during heat engines, lightning absorbers during lightning's strikes, vibration energy during heavy machinery. The main focus of our paper is to convert the kinetic energy from human footsteps into electrical energy.

This conversion is done by using the rack and pinion model consisting of a dynamo. Although this gives high voltages it is very expensive and cannot be applicable for multiple units, therefore this piezoelectric model is developed. This piezoelectric model consists of piezoelectric sensors made of lead zirconium titanate, which is the best man-made piezo electric material.

Piezoelectricity is a major principle in the energy scavenging sector due to its ability to convert any extreme pressures and kinetic movements into electrical energy

\section{Piezoelectricity}

\subsection{Piezoelectric effect}

The piezoelectric effect can be seen as a conversion between mechanical and electrical energies (Songsukthawan, 2017). When crystals of certain elements are exposed to mechanical pressure, an atomic deformation causing a shrink in the potential barrier is observed. This causes dipole transfer thus creating an electric field and producing the voltage difference

These materials are called piezoelectric materials and the effect is called direct piezo electric effect as shown in Fig. 1 below.

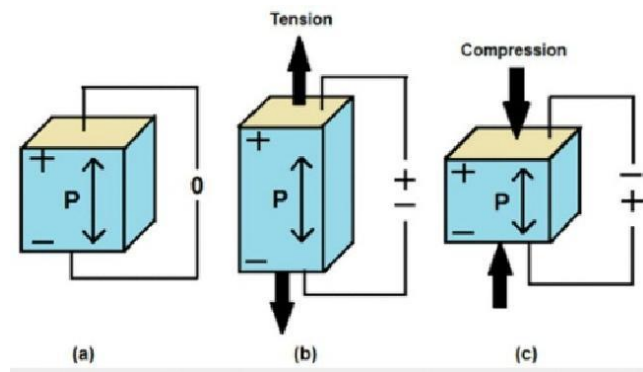

Figure 1. Direct piezoelectric effect 
The piezo electric effect is completely dependent on the direction and movement of the electric fields and the mechanical deformation.

\subsection{Lead Zirconium Titanate (PZT)}

PZT sensors are the most common and economical man-made piezoelectric materials used for energy conversion processes (Kumar, 2014; Garikipati, 2021). This type of sensors is known to have the highest Curie point, high piezoelectric coefficient, highly polarized due to their atomic structure.

Table 1. PZT properties

\begin{tabular}{|l|l|}
\hline Properties & Quantity \\
\hline Relative Dielectric Constant & 1645 \\
\hline Piezoelectric coefficients d33 & $390 \times 10^{-12} \mathrm{~m} / \mathrm{V}$ \\
\hline Piezoelectric coefficients d31 & $-190 \times 10^{-12} \mathrm{~m} / \mathrm{V}$ \\
\hline Curie temperature & $300^{\circ} \mathrm{C}$ \\
\hline Capacitance & $203 \mathrm{mph}$ \\
\hline Open circuit voltage & $13 \mathrm{v}$ \\
\hline Rated frequency & $47 \mathrm{~Hz}$ \\
\hline
\end{tabular}

The PZT sensors used here are Q220-A4-503YB (Piezo System, Inc.), dual configuration with outer brass reinforcement; the charge is developed when one plate is compressed and another plateis stretched and the charge in each layer is then stored at the brass layer.

The PZT sensors used here are capable of generating max voltage of $13 \mathrm{v}$ with max current rating of 200 microamperes.

\section{Theoretical Calculations}

\subsection{Assumptions}

Force exerted is 1.3 times weight

Acceleration of gravity value $10.0 \mathrm{~m} / \mathrm{sec}^{\wedge} 2$

Weight of one person is $80 \mathrm{KG}$

Tile's displacement $0.01 \mathrm{~m}$

Each tile has $50 \%$ efficiency

Total distance is $75 \mathrm{ft}$

$1.5 \mathrm{ft}$ stride between the steps

Calculation

$$
1 \mathrm{KWh}=3.6 \times 10^{6} \mathrm{~J}
$$

Weight $=80 \mathrm{~kg}$

Force $=\mathrm{w}^{*} \mathrm{~g}=80 * 10=800 \mathrm{~N}$

Force exerted per tile

$\mathrm{F}=1.3 \times 800 \mathrm{~N}$

$\mathrm{F}=1019.2 \mathrm{~N}$

Now find energy per step by multiplying this energy by the displacement of tile i.e.

Energy $=1019.2 \times 0.01 \mathrm{~m}$ 
Energy $=10.192 \mathrm{~J}$

The efficiency of each tile is $50 \%$ so energy will be Energy $=5.096 \mathrm{~J}$

As we have approximated that the distance at which if we have installed our system is $75 \mathrm{ft}$ and stride is $1.5 \mathrm{ft}$ then

Total energy $=5.096 \mathrm{~J} * 75 \mathrm{ft} / 1.5 \mathrm{ft}$

Total energy $=254.8 \mathrm{~J}$

Now convert this energy to total units produced by a single person i.e.

Units produced $=254.8 \mathrm{~J} / 3.6 \times 10^{6}$

Units produced $=0.0000707 \mathrm{KWh}$

This is theno. of units produced by a single person i.e.

Units produced by a person $=0.0000707$.

Let the total numbers of people include students, faculty, lab staff and works are 2500 and they passthrough that area 4 times in a day so

Units produced in a day $=0.0000707 * 10,000$

Units produced in a day $=0.707 \mathrm{kWh}$.

*Although the efficiency is considered as $50 \%$ efficiency of the practical model depends upon various factors and might be far below the expected value.

\subsection{Maximum voltage generated}

When a pressure is applied on piezo material, a charge is generated across its edges. Thus, it can be assumed to be an ideal capacitor. All equations governing capacitors can be applied to it. In this research work, three series connected piezoelectric crystals placed under a tile and ten such series connections are shunted together. The net voltage generated under one tile is equal to the sum of individual voltages generated across each piezoelectric disc. Output voltage from 1 piezoelectric disc is 13 volts .It produces the maximum voltage of 39 volts, if three piezo electric discs are connected in series

\section{Construction}

\subsection{Study of connection}

The piezo electric sensors are connected in a parallel and series connection to increase the generated voltage and also improves the current waveform. This arrangement also allows us applying the proper force on the sensors by the wooden board. This connection allows us to generate maximum voltage out of minimum force exerted. The series and parallel connection also provides a proper distribution of the force exerted from the plank.

\subsection{Structure and PZT arrangement}

There are two wooden planks each of size 12 × 15 inch, these planks are used for mechanical stability and to act as the base for the footstep.

The two planks are supported by 4 springs of 5 inch height which provide the ability for smooth movement and don't need any manual resetting after each and every use. These springs allow minimal backlash on to the foot considering a movement height of 3 inch providing the person with a minimal cumulative force (Arunkarthikeyan, 2021). So the person can just walk on to the wooden blank with no preliminary thought.

The springs are fixed on to the plank by screws and for more rigidity; hot glue can be used to reduce the momentary spring displacement (Pavan, 2020; Arunkarthikeyan, 2020). This allows no sideward movement for the springs therefore removing any wobbling action during the placement of the footstep.

The upper plank is then placed on to this spring and also on the four sides of the base plate (Pavan, 2020; Ezhilarasi, 2020). The series and parallel connected arrangement of the piezoelectric plates are then placed on a raised base made of wood (Balamurugan, 2018). Then a few rubber corks are fixed on to the upper layer on the raised piezo plates which reduces the plank movement but still generates the same force. 


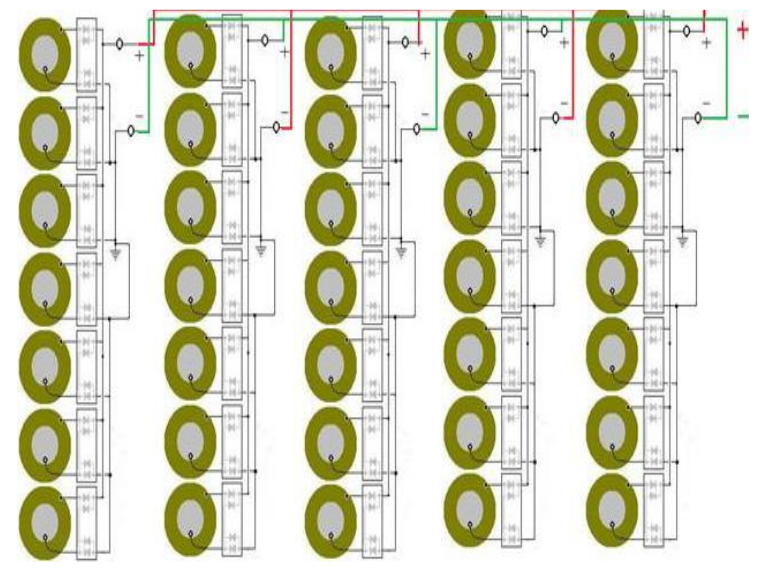

Figure 2. Series and parallel connection of PZT sensors

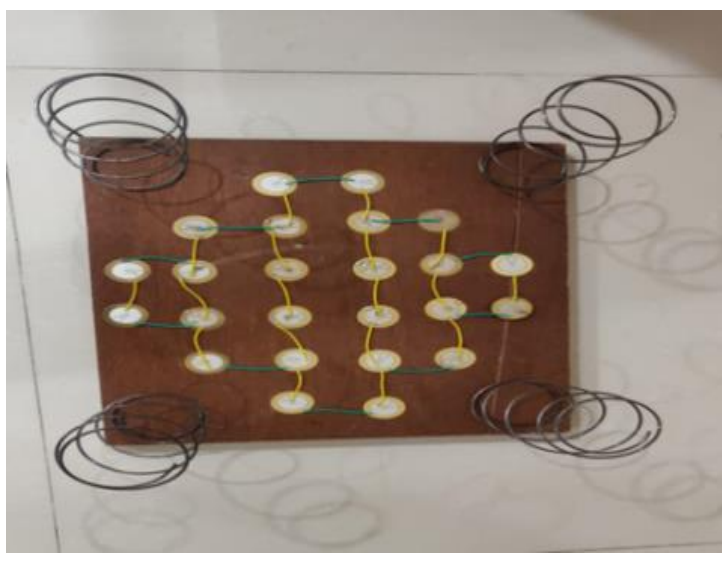

Figure 3. Top view of sensor and spring arrangement

After that the two output terminals from the above setup are taken and given to the Arduino analog input pins. The Arduino and the LCD screen are other part of the setup. They both constitute to the software of the FSPG. The Arduino and LCD screen are both mounted on the beard board with necessary connections made. Thus, the footstep power generator is ready to test for power generation and a rechargeable battery is used to store the energy.

\subsection{Block diagram}

As shown in the block diagram the completed model of the generator is then connected to the ripple neutralisers and diodes then interfaced to the Arduino through the voltage regulator which is required to maintain the operating voltage of Aurdino in the range of $5 \mathrm{~V}-7 \mathrm{~V}$. This is used for monitoring the output and to indicate the number of steps .

Table 2. Voltage generated per step

\begin{tabular}{|c|c|c|c|}
\hline S. No & Weight in Kgs & Voltage generated & Power generated \\
\hline 1 & 10 & $0.1 \mathrm{~V}$ & $0.00013 \mathrm{~W}$ \\
\hline 2 & 20 & $0.2 \mathrm{~V}$ & $0.00026 \mathrm{~W}$ \\
\hline 3 & 60 & $4.38 \mathrm{~V}$ & $0.0057 \mathrm{~W}$ \\
\hline
\end{tabular}




\begin{tabular}{|c|c|c|c|}
\hline 4 & 70 & $7.69 \mathrm{~V}$ & $0.01 \mathrm{~W}$ \\
\hline 5 & 80 & $14.6 \mathrm{~V}$ & $0.02 \mathrm{~W}$ \\
\hline
\end{tabular}

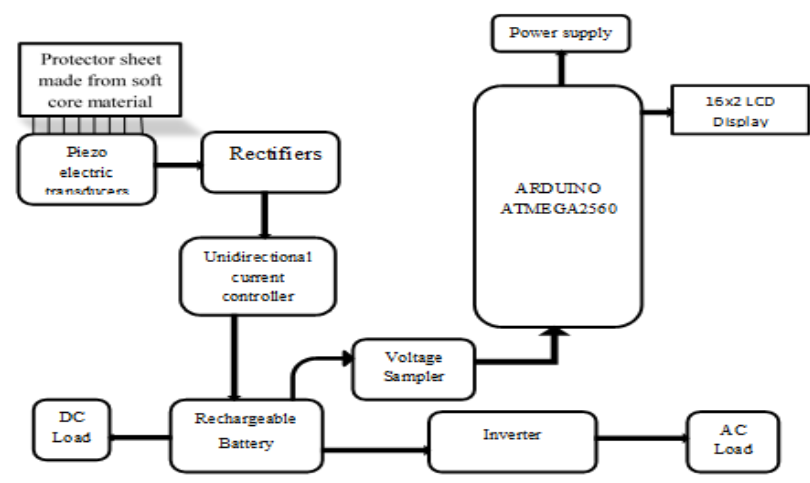

Figure 4. Block Diagram

In the block diagram shown in the Fig. 4,the generator is interfaced with Arduino. This monitoring system can be used for multiple tiles therefore reducing the cost of control and monitoring systems. The AC output of the generator is actually passed to the rechargeable battery through a rectifier and diodes.

\section{Principle of Working}

The principle of working of the foot step power generation device is that if a person who weigh's more than $60 \mathrm{kgs}$ is allowed to walk on the tile, develops a mechanical movement due to the compression of the springs below the upper tile. When the upper tile is pressed on to the PZT sensors connected in series and parallel, it produces an alternating current in the sensors for a few seconds or less due to the piezoelectricity (Chinnamahammad bhasha, 2020; Balamurugan, 2020). When the person walks or runs on the rubber corks or stubs which are placed on the PZT sensors increases the impact pressure applied by the upper tile

The LCD screen and Arduino MEGA 2560 microcontroller setup is used to know how much voltage is been stored by the battery and to count the number of steps that are applied on the tile. The program Code in C language is written to display the voltage stored per step and for the number of steps. Arduino takes both analog as well as digital inputs. So, a separate ADC is not required in the circuit as Arduino itself has an in-built ADC (Balamurugan, 2017; Balamurugan, 2020; Usha, 2019)

The supply to the Arduino should be constant but not pulsating so a Voltage sampler is used to set the voltage curve at desired level i.e. 5V. Normally supply to the Arduino board is given by USVB cable through which the board is interfaced with the computer to dump the code to display the voltage. The $5 \mathrm{~V}$ power supply is supplied to the Arduino board and to the LCD screen. Hence when a person walks or runs on the tile, power is generated on the sensors and is stored in battery and at the same time power is supplied to the Arduino and the number of steps and voltage stored per step is displayed.

This is the flow chart for the Arduino monitoring and display of the output from the footstep generator

\section{Flowchart for Arduino Code}

As it can be seen the interfacing and coding is an important component for the monitoring and control of the generator.

The combination of Arduino mega and the LCD screen allows for a systematic display to indicate the voltage and no. of steps after each display, waits for the next input owing to the loop. 


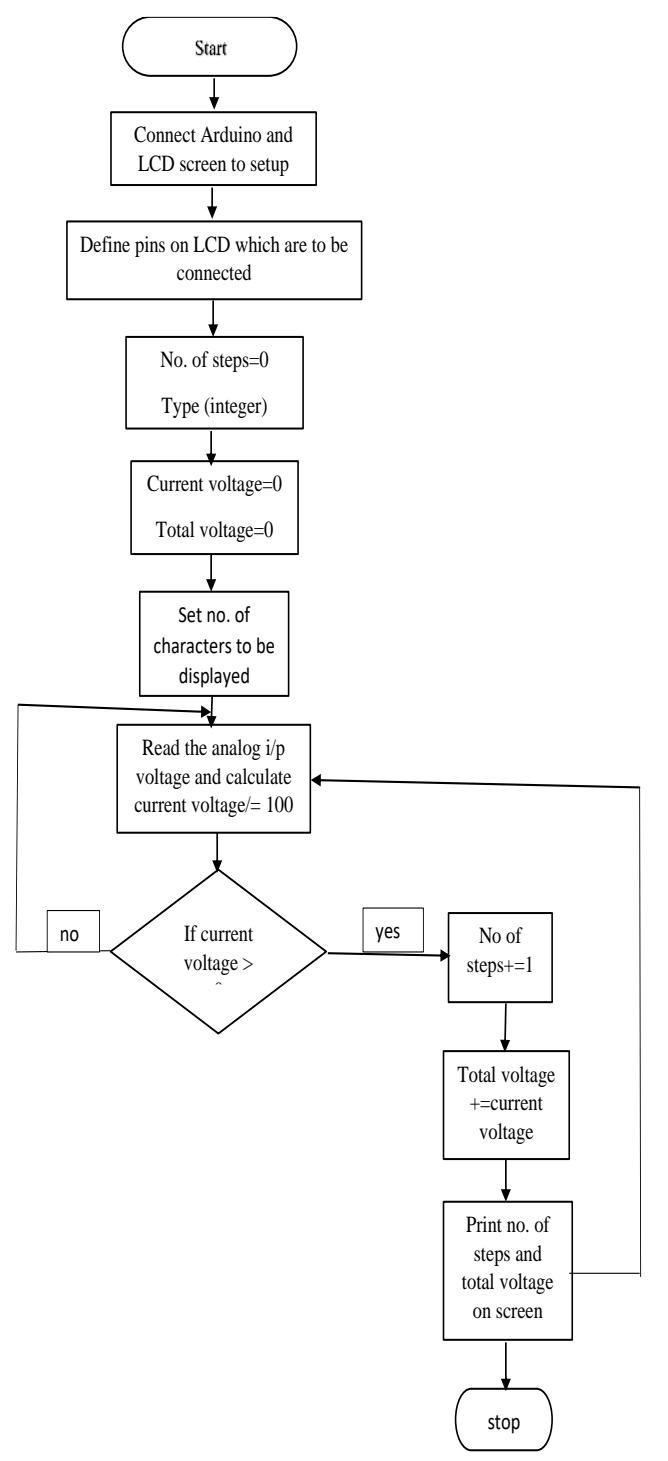

Figure 5. Flow chart of the Arduino working

\section{Results and Discussion}

The results in the above table are a part of the testing done on a practical arrangement with the abovementioned specifications.

The Table 2.highlights the amount of voltage generated

for various amounts of weight of the footsteps landing on the upper tile.

The power for each footstep of varying weights is calculated based on the efficiency of the tile and other parameters. This power can also be seen by connecting a power meter at the output. Since the output is very momentary the reading of the power meter might be prone to errors.

The major aspect of concern is that although the voltage is sufficiently good for each step the current rating is low therefore power generated is very low per step.

From the Table2.we can understand that the weight of the footstep plays a very key role in the amount of voltage generated. The voltage generated gets doubled with an increased weight of $10 \mathrm{~kg}$ 's and this is due to the ramping effect of the piezoelectric sensors where at high pressures the dipole movement is larger and therefore more voltage is required.

Since not every footstep can give $80 \mathrm{~kg}$ of force the average output over a number of steps can be taken as 9.3 volts taking the efficiency of the arrangement into consideration.

Table 3. Power generated for the $\mathrm{n}$ number of steps

\begin{tabular}{|l|l|}
\hline No. of Steps & Power (Watts) \\
\hline
\end{tabular}




\begin{tabular}{|l|l|}
\hline 250 & 2.6 \\
\hline 500 & 5.4 \\
\hline 1000 & 11.3 \\
\hline 10000 & 100 \\
\hline
\end{tabular}

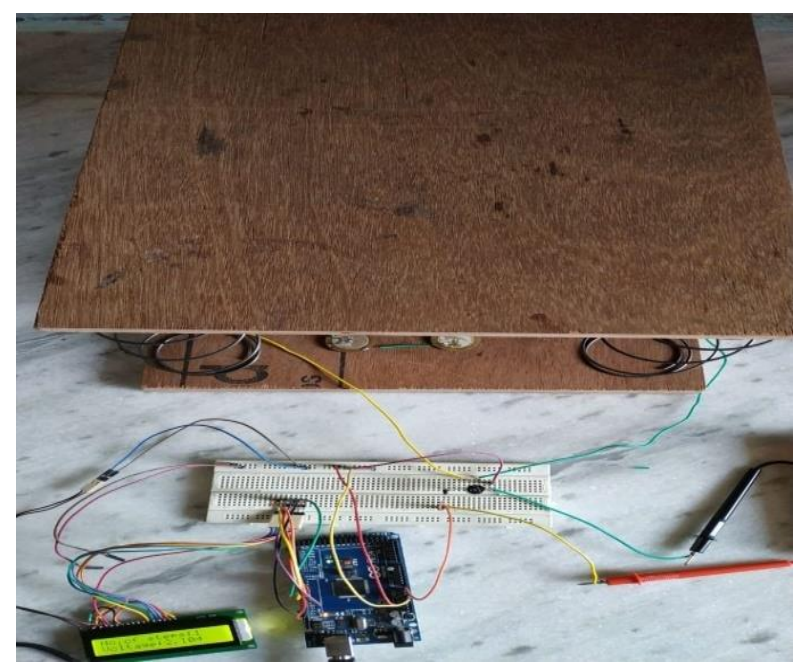

Figure 6. Practical arrangement of piezoelectric generator

Now from the results we can say that the output of a single unit is considerably low for direct use but this single unit when left out for a month can at least provide a minimum of 60 to 70 units of power at the lowest output per step.

Therefore, it can made as secondary source to use in case of power failures and to use as battery packs. Although this output cannot be directly used for powering small devices and requires many transformations therefore it can made available for smaller output amplifiers which can be used to power mobile phones.

Inverters and ADC's, rectifiers are used to store the generated voltage into the lead acid battery. When this setup is installed in a large area consisting of multiple units and huge availability of footsteps, the output is multiplied considerably.

The great advantage of the footstep generators is that they are considerably cheaper to build a combined monitoring system. Is designed for the analysis of the number of steps and voltage generated. This analysis can be further extended to additional sensors on the overboard of the generator like the body temperature of the humans. The force exerted is although a bit costly the geo location of a human can be identified anywhere near the array of piezoelectrical generators.

\section{Conclusions}

The footstep power generation is not a completely dependable source but it is still a first-class secondary source which can be used in tandem with solar or thermal and this setup can be further used in crowded areas like exhibitions

In this method only the electrical part plays a major role. Thus, the method is quite easy to implement and maintain. But to implement the whole system for urban area, more design parameters should be considered.

This paper aims to show that the power generation by this method is a sufficient substitute for charging small gadgets and street lights.

Although the system is made of wood which provides much required durability but it is prone to severe decay when placed underground therefore it needs an exchange of plank after the considerable use.

The analysis is made for a single unit and this project can be replicated in to many units and the entire footpaths can be connected to a single monitoring system for localized data and then this output can be stored into huge battery packs. 


\section{References}

1. Arunkarthikeyan K., and Balamurugan K. (2021) Experimental Studies on Deep Cryo Treated Plus Tempered Tungsten Carbide Inserts in Turning Operation. In: Arockiarajan A., Duraiselvam M., Raju R. (eds) Advances in Industrial Automation and Smart Manufacturing. Lecture Notes in Mechanical Engineering. Springer, Singapore. https://doi.org/10.1007/978-981-15-4739-3_26

2. Arunkarthikeyan, K. and Balamurugan, K., (2020) July. Performance improvement of Cryo treated insert on turning studies of AISI 1018 steel using Multi objective optimization. In 2020 International Conference on Computational Intelligence for Smart Power System and Sustainable Energy (CISPSSE) (pp. 1-4). IEEE.

3. Balamurugan K. (2020) Metrological changes in surface profile, chip, and temperature on end milling of M2HSS die steel. International Journal of Machining and Machinability of Materials, 22(6):pp. 443-453.

4. Balamurugan K and Uthayakumar M, (2017) Preparation And Machining Studies Of Lapo4 Y2o3 Ceramic Matrix Composite, http://hdl.handle.net/10603/166221.

5. Balamurugan K, Uthayakumar M, Sankar S, Hareesh US, Warrier KG. (2020) Process optimisation and exhibiting correlation in the exploitable variable of AWJM. International Journal of Materials and Product Technology, 61(1), pp.16-33.

6. Balamurugan K, Uthayakumar M, Sankar S, Hareesh US, Warrier KG. (2018) Preparation, characterisation and machining of LaPO4-Y2O3 composite by abrasive water jet machine. International Journal of Computer Aided Engineering and Technology, 10(6), pp.684-697.

7. Chinnamahammad bhasha A, and Balamurugan, K. (2020) Fracture analysis of fuselage wing joint developed by aerodynamic structural materials." Materials Today: Proceedings, Vol.38, pp. 2555-2562.

8. Ezhilarasi TP, Dilip G, Latchoumi TP, Balamurugan K. (2020) UIP-A Smart Web Application to Manage Network Environments. InProceedings of the Third International Conference on Computational Intelligence and Informatics, pp. 97-108. Springer, Singapore.

9. Garikipati P, and Balamurugan K. (2021) Abrasive Water Jet Machining Studies on AlSi 7+63\% SiC Hybrid Composite. InAdvances in Industrial Automation and Smart Manufacturing, pp. 743-751, Springer, Singapore.

10. Kumar, D., Chaturvedi, P., Jejurikar, N. (2014) Piezoelectric energy harvester design and power conditioning 2014 IEEE Students' Conference on Electrical, Electronics and Computer Science, Bhopal,:1-6.

11. Pavan MV, Balamurugan K, Balamurugan P. (2020) Compressive test Fractured Surface analysis on PLA-Cu composite filament printed at different FDM conditions. InIOP Conference Series: Materials Science and Engineering, Vol. 988,pp. 012019. IOP Publishing.

12. Pavan MV, and Balamurugan K. (2020) Compressive Property Examination on Poly Lactic Acid-Copper Composite Filament in Fused Deposition Model-A Green Manufacturing Process. Journal of Green Engineering.10, pp.843-852.

13. Songsukthawan, P., Jettanasen, C. (2017) Generation and storage of electrical energy from piezoelectric materials, IEEE 3rd International Future Energy Electronics Conference and ECCE Asia (IFEEC 2017 ECCE Asia), Kaohsiung, 2017:2256-225.

14. Usha Kiruthika, S., Kanaga Suba Raja, S., Balaji, V., Raman, C.J., Durai Arumugam, S. S. L., (2019) Detection of Tuberculosis in Chest X-rays using U-Net Architecture', International Journal of Innovative Technology and Exploring Engineering, ISSN: 2278-3075, 9 (1): 2514-2519.

15. 